\title{
Correspondence
}

\section{Glucose intolerance in cystic fibrosis}

Sir,

Stutchfield et al in their studies of glucose intolerance in children with cystic fibrosis report pancreatic islet cell antibodies in five of 24 patients with glucose intolerance identified by raised glycated haemoglobin $\left(\mathrm{HbA}_{1}\right) .{ }^{1}$ They suggest that an autoimmune response to damaged pancreatic tissue may promote the development of glucose intolerance. We would like to suggest a further factor that appears to influence glucose tolerance and may be relevant to the interpretation of glucose tolerance tests and the subsequent development of insulin dependent diabetes in cystic fibrosis.

We have recently reported a modified Ussing chamber technique to study ion transport in the cystic fibrosis enterocyte using jejunal biopsy tissue. ${ }^{2}$ The basal potential difference, short circuit current, and resistance of 22 control biopsy specimens and 11 biopsy specimens from patients with cystic fibrosis are shown in fig 1 . Initial differences in potential difference and short circuit current probably reflect basal secretion in the control tissues, which is absent in epithelia in cystic fibrosis. Both chloride secretion and nutrient absorption are active electrogenic processes whose activation can be detected as a rise in short circuit current. All control biopsy specimens responded to the stimulation of chloride secretion by acetylcholine with an increase in short circuit current but the specimens from patients with cystic fibrosis failed to exhibit such a response (fig 2 ). This indicates the lack of a functioning chloride secretory mechanism similar to that observed in other affected epithelia. ${ }^{3}$ Both control biopsy specimens and those from patients with cystic fibrosis generated an increase in short circuit current when glucose was added to the luminal surface but this effect was significantly greater in the specimens from patients with cystic fibrosis. This suggests that glucose uptake is enhanced in cystic fibrosis, an observation that has also been
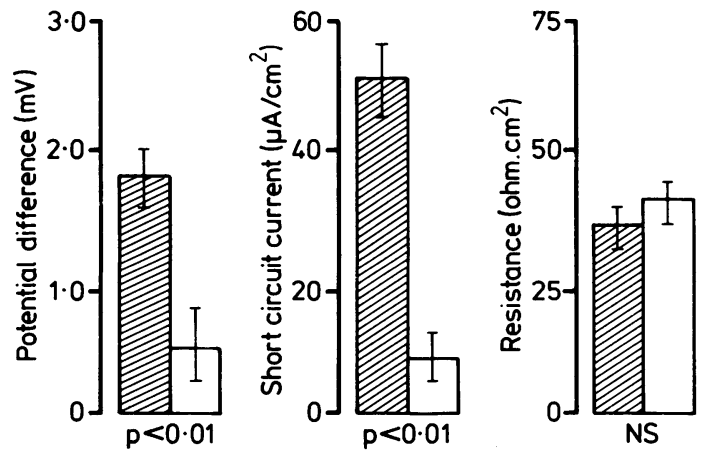

Fig 1 Bar diagram showing mean (SE) basal electrical activities of jejunal tissue from controls (hatched) and patients with cystic fibrosis (clear).

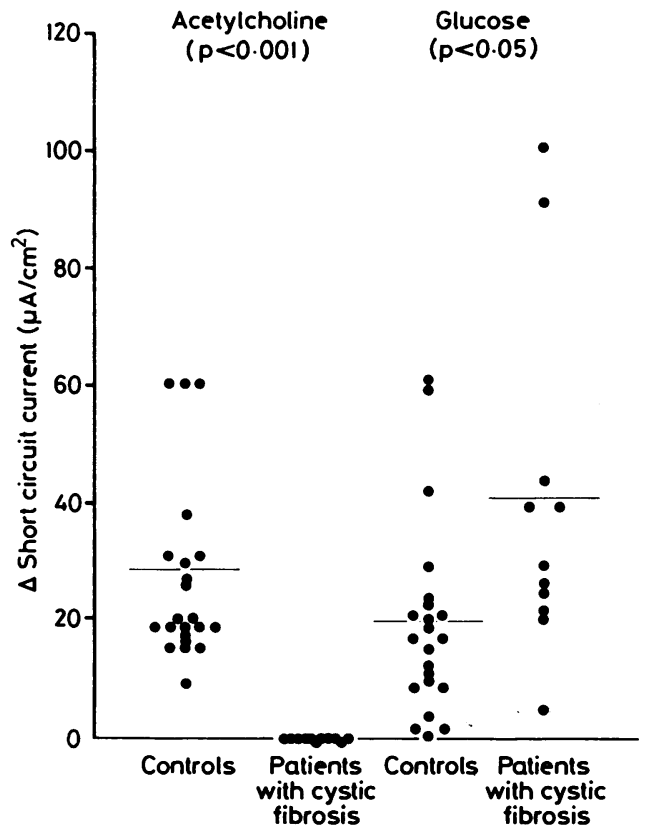

Fig 2 Response ( $\Delta$ short circuit current) to secretagogue challenge (acetylcholine, $10^{-3} \mathrm{M}$ ) and mucosal glucose $\left(10^{-2} \mathrm{M}\right)$ in biopsy specimens from controls and patients with cystic fibrosis.

noted in in vivo perfusion studies. ${ }^{4}$ The relative glucose intolerance seen in cystic fibrosis may therefore be a consequence of an increased rate of glucose absorption.

\section{References}

1 Stutchfield PR, O'Halloran SM, Smith CS, Woodrow JC, Bottazzo GF, Heaf D. HLA type, islet cell antibodies, and glucose intolerance in cystic fibrosis. Arch Dis Child 1988;63:1234-9.

2 Taylor CJ, Baxter PS, Hardcastle J, Hardcastle PT. Failure to induce secretion in jejunal biopsies from children with cystic fibrosis. Gut 1988;29:957-62.

${ }^{3}$ Frizzell RA, Rechkemmer G, Shoemaker RL. Altered regulation of airway epithelial cell chloride channels in cystic fibrosis. Science 1986;233:558-60.

${ }^{4}$ Frase LL, Strickland AD, Kachel GW, Krejs GJ. Enhanced glucose absorption in the jejunum of patients with cystic fibrosis. Gastroenterology 1985;88:478-84.

C J TAYLOR and P S BAXTER Department of Paediatrics, Sheffield Children's Hospital, Sheffield S10 2TH

J Hardcastle, P T Hardcastle, and J Goldhill Department of Biomedical Science, University of Sheffield S10 2TN 